\title{
Complete Regression of a Melanocytic Nevus under Intense Pulsed Light Therapy for Axillary Hair Removal in a Cosmetic Center
}

\author{
José M. Martín ${ }^{a} \quad$ Carlos Monteagudo ${ }^{b}$ Rebeca Bella ${ }^{a} \quad$ Irela Reig $^{a} \quad$ Esperanza Jordáa \\ Departments of a Dermatology and ${ }^{b}$ Pathology, Hospital Clínico Universitario de Valencia, Valencia, Spain
}

\section{Key Words}

Intense pulsed light $\cdot$ Laser .

Pseudomelanoma $\cdot$ Regression •

Melanocytic lesions

\begin{abstract}
Intense pulsed light (IPL) therapy using noncoherent broad-spectrum light has been reported to be effective for hair removal, and also for treating superficial pigmented lesions like ephelides and solar lentigines. We report complete regression of a pigmented melanocytic nevus, histologically confirmed, after hair removal treatment with IPL. The use of lasers and IPL is a common procedure used by dermatologists and even other professions for the treatment of cosmetically troubling skin conditions. The main advantage of such treatment is a reduction of surgical scars, thus producing a favorable cosmetic outcome, but a major limitation is that histopathologic diagnosis is not usually obtained prior to treatment. Such devices should be carefully used in patients with potentially dangerous melanocytic lesions. We also review the recent literature regarding inadequate treatment of melanocytic lesions with lasers.
\end{abstract}

Copyright ๑ 2012 S. Karger AG, Basel

\section{Introduction}

The use of lasers and intense pulsed light (IPL) technology has become established practice in dermatology and aesthetic medicine. The number of treatments performed with lasers and IPL has experienced a notable increase in the last two decades [1]. Unfortunately, the increase in popularity and widespread use of such equipment, sometimes used by cosmetologists and aestheticians, has been accompanied by a sharp increase in the number of professional errors $[1,2]$. The consequences can be severe if cutaneous lesions are improperly treated by staff with limitations in dermatology skills. In this context, treatment of dysplastic nevi during photoepilation must be mentioned.

\section{Case Report}

A 42-year-old woman with multiple acquired melanocytic nevi was regularly evaluated in our Department of Dermatology using digital dermoscopy. In one of her routine revisions, dermoscopy revealed that one of her nevi, located on the left axilla, had significantly changed since her last visit. This melanocytic nevus, which initially measured $6 \mathrm{~mm}$ and was dark-brownish in color (fig. 1a), showing a homogeneous reticular pattern on dermoscopy (fig. 1b), had virtually lost all the aforementioned features. Dermoscopy showed several blotches of brownish pigment without any reminiscent pattern of a melanocytic lesion, together with centrally located slight whitish areas mimicking regression or scarring. A very subtle reticule could only be seen at the periphery (fig. 1c). Anamnesis revealed that the patient had undergone eight IPL sessions to remove the hair from her axillae in a cosmetic center. The sessions were performed every five weeks, and she realized that the nevus changed over the last two sessions.

We initially decided on observation and careful follow-up of the patient. Three months later, the lesion showed similar characteristics. The brownish spots of pigment were smaller, and new brownish dots, in a diffuse distribution, could also be seen together with whitish areas (fig. 1d). Therefore, we decided to remove the lesion.

Histologically, the epidermis showed a slight acanthosis and papillomatosis, and prominent basket-wave hyperkeratosis with small superficial microcrusts. Delicate fibrosis, few perivascular lympho-

\section{KARGER}

Fax +4161306 1234 E-Mail karger@karger.ch www.karger.com
(C) 2012 S. Karger AG, Basel

1018-8665/12/2243-0193\$38.00/0

Accessible online at: www.karger.com/drm
Dr. José M. Martín

Hospital Clínico Universitario de Valencia

Avda Blasco Ibáñez, nº 17

ES-46010 Valencia (Spain)

E-Mail jmmart@eresmas.com 
cytes, and aggregates of melanophages were present in the papillary dermis (fig. 2, 3). No junctional or dermal melanocytic nests were found. Melan-A immunostaining disclosed a normal periodical distribution of epidermal melanocytes. Melanophages were found in the dermis where no MelanA-labeled melanocytes were present.

\section{Discussion}

Melanin is synthesized in tyrosinasecontaining melanosomes within melanocytes. Human melanocytes rapidly transfer the produced melanin to keratinocytes and do not accumulate it. These melanosome accumulations (melanosome clusters or packaged melanosomes) form caplike structures over the nuclei of keratinocytes to protect the nuclei from the damaging effects of ultraviolet radiation. The highest density of melanin is present in the epidermal basal layer as supranuclear melanin caps [3].

Melanin absorbs a wide range of light, making different light sources useful for melanocytic lesion removal, including argon, ruby, alexandrite, Nd:YAG, and more recently, noncoherent intense pulsed flashlamps. IPL is a broadband visible light emitted from a noncoherent, filtered flashlamp. IPL sources emit light in the 500$1,200 \mathrm{~nm}$ range and allow hair removal, treatment of vascular lesions, and removal of either superficial or deep melanocytic lesions [4].

The target of IPL treatment of melanocytic lesions is the melanosome. Selective thermal damage has been observed with a wide range of wavelengths, from 351 to $1,064 \mathrm{~nm}$. Long wavelengths are able to penetrate more than $3 \mathrm{~mm}$ and are suitable for dermal melanocytic lesion removal. On the contrary, short wavelengths reach $200 \mathrm{~nm}$ beneath the epidermis and are safe for treatment of superficial melanocytic lesions due to preservation of the dermis. The use of long wavelength would explain why epidermal melanocytes persisted in this case. The IPL pulse duration is on the order of milliseconds. In considering the thermal relaxation time of a melanosome, selective photothermolysis requires a pulse duration of nanoseconds (70$250 \mathrm{~ns}$ ). Long pulses, greater than the melanosome thermal relaxation time, may provoke thermal diffusion from melanosomes to their surroundings, with potential deleterious side effects, and may stim-
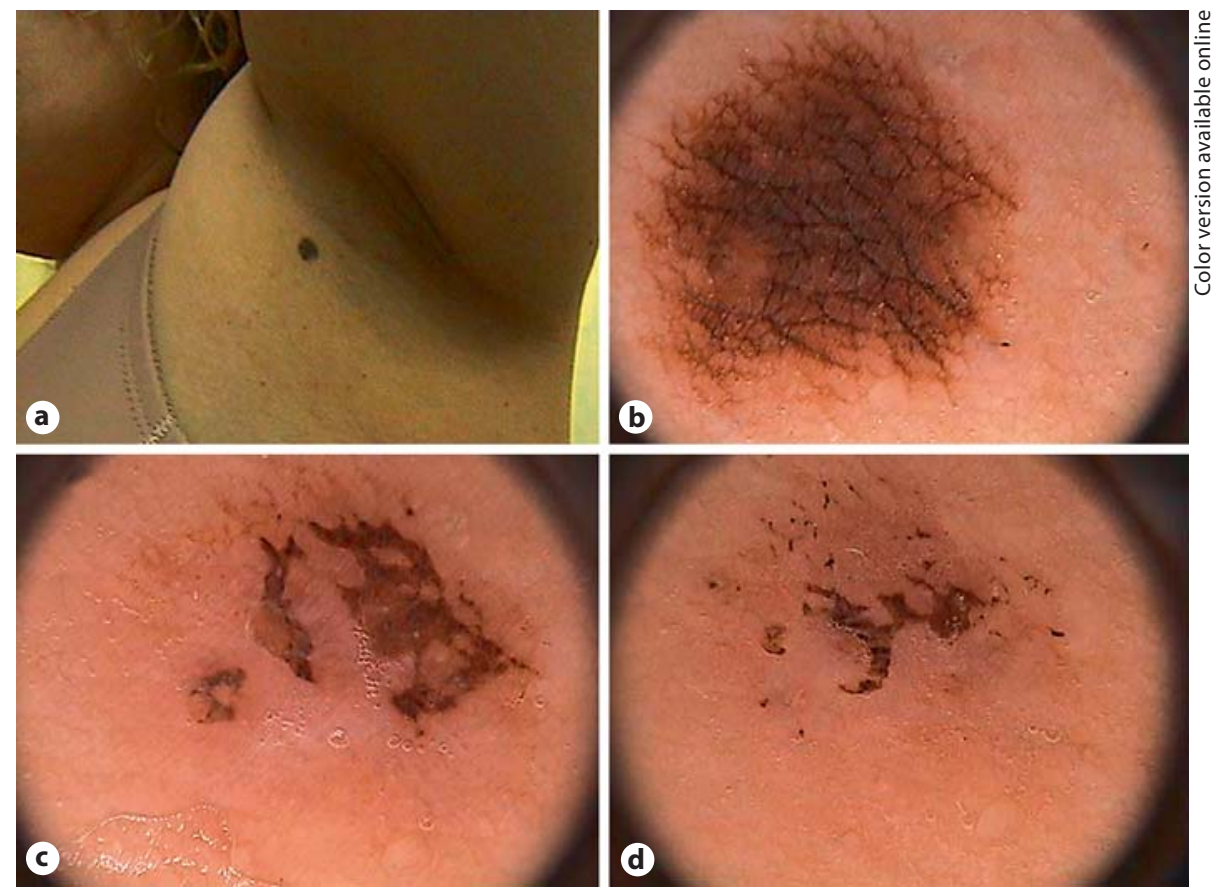

Fig. 1. Clinical (a) and dermoscopic (b) morphology of the nevus prior to treatment with IPL. c Dermoscopic morphology after 8 sessions of IPL treatment. $\mathbf{d}$ Dermoscopic picture 3 months after the end of IPL treatment.

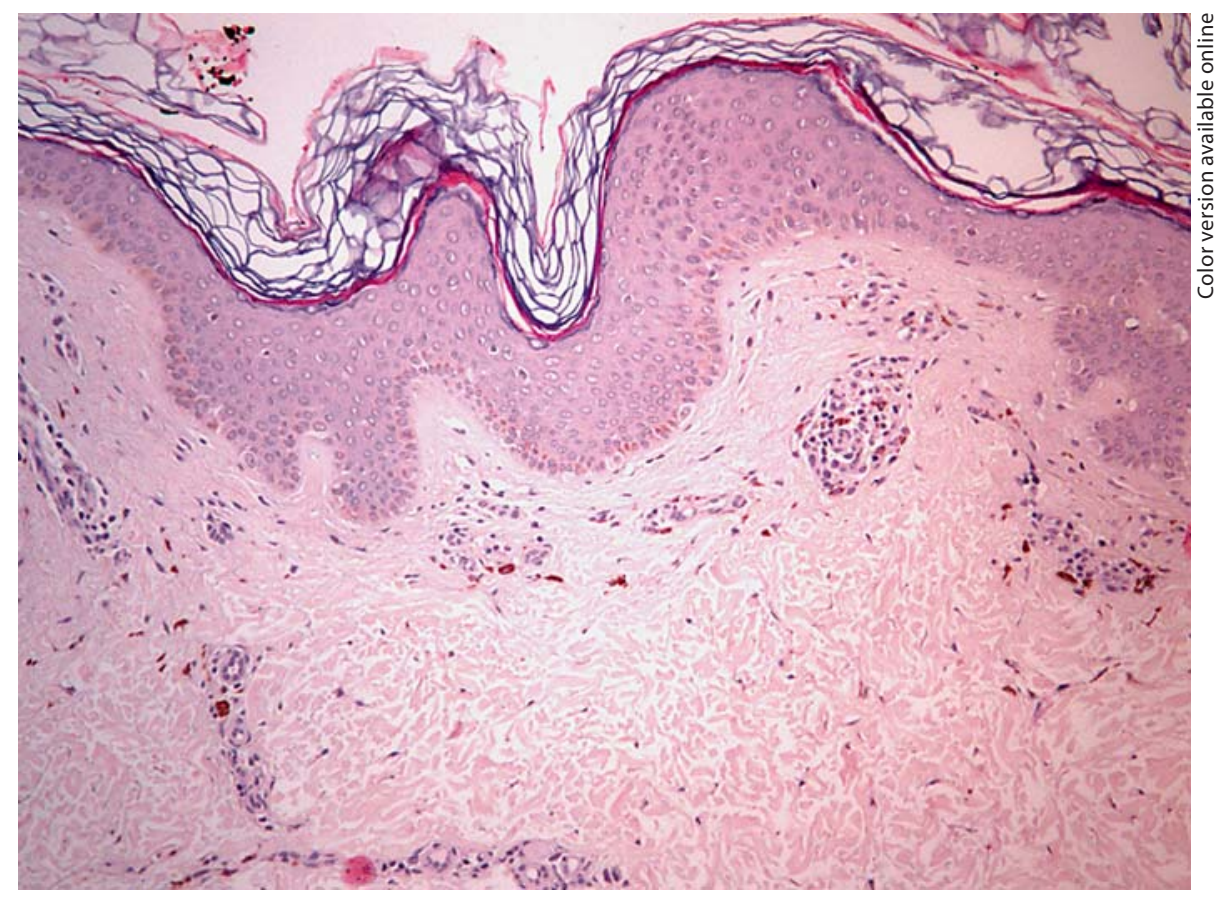

Fig. 2. Low-power magnification showing slight epidermal hyperplasia with hyperkeratosis. H\&E, $\times 40$. 
ulate a rapid differentiation of epidermal cells by heating effects [4].

Regarding the dermoscopic-pathologic correlation in this case, the brownish blotches of crusted pigmentation shown with dermoscopy could be probably related to the microcrusts shown by reflectance mode confocal microscopy after treatment of solar lentigines and ephelides with IPL [5].

Electron microscopy studies have analyzed the microscopic structure of these microcrusts, showing that they were composed of numerous melanosomes together with cellular debris. The microcrusts usually appeared on day 5 after IPL irradiation. The mechanism of IPL photothermolysis of pigmentary lesions consists of denaturation of melanin caps-containing cells and promotion of a rapid differentiation of keratinocytes, accompanied by an upward transfer of melanocytes along with necrotic keratinocytes, which results in the elimination of melanosomes as the microcrusts are removed from the skin [5].

Microcrusts could not be seen on the adjacent non-pigmented skin, and their formation seemed to depend on the amount and density of pigments contained in the lesion. They usually disappear within two weeks after irradiation [6]. We do not have any plausible explanation for the persistent accumulation of the microcrusts in this patient because she denied new pulsed light sessions. Otherwise, these microcrusts are not a feature associated to spontaneous regression of melanocytic nevi.

The slight whitish areas appreciated dermoscopically would correspond histologically to a particular type of fibrosis composed of bundles of extremely fine and ordered collagen fibers present in the papillary dermis. This subtle fibrosis, very unusually seen in the histopathological evaluation of regression in melanocytic nevi, may be explained by the exposition of IPL and may be related to the rapid evolution of the regression process.

The increased use of lasers and light sources for the removal of pigmented skin lesions may lead to a growing risk of erroneously treated melanocytic tumors. In recent years, several errors (or complications) related to laser treatment of melanocytic lesions have been reported [1,7-21]. Although lentigines and café au lait spots are frequently managed with IPL [4], there are few cases of melanocytic nevi treated with this technique in the literature, main-

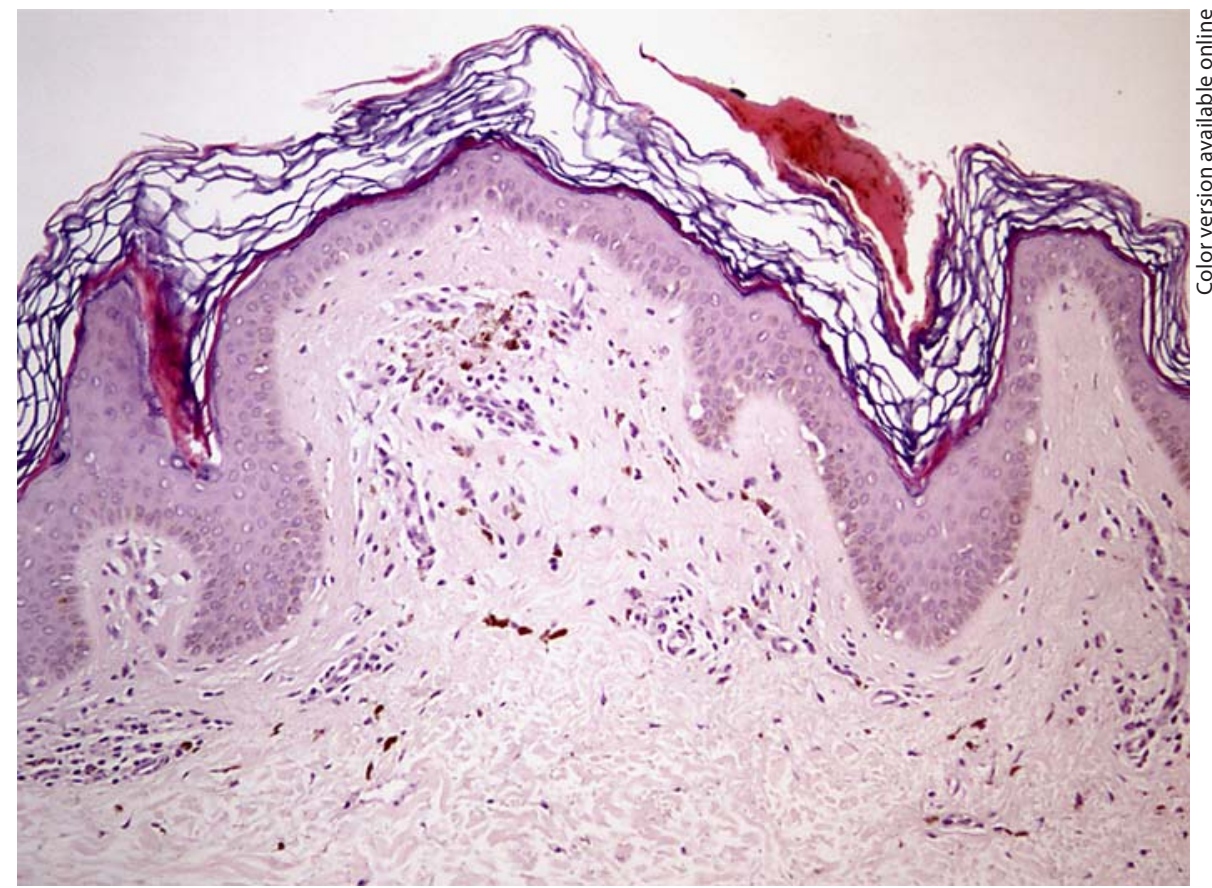

Fig. 3. A microcrust was present in the epidermis above a papillary dermis with delicate fibrosis and a mild superficial inflammatory component with melanophages. H\&E, $\times 100$.

ly because the use of laser therapy and IPL in the treatment of pigmented melanocytic lesions is a controversial issue. A complete regression of melanocytic nevi after laser treatment, as occurred in our case, is not usually described.

IPL and melanin-targeting lasers can eliminate superficial melanocytes. However, reported studies about laser treatment of melanocytic lesions show that, in most cases, the complete removal of melanocytic nevi cannot be obtained either clinically or histologically, so repigmentation is frequently seen $[2,8,13,14]$. Ablative systems such as $\mathrm{CO}_{2}$ and argon lasers are not pigment-specific and carry a special risk of relapse [2].

Some publications about misdiagnosis induced by laser therapy reported socalled pseudomelanoma [7-10]. The term pseudomelanoma has been used to describe a lesion that histologically resembles superficial spreading melanomas and is clinically seen as areas of repigmentation. It typically occurs following incomplete treatment of a melanocytic nevus either by surgery, dermabrasion or laser therapy $[2,13,14]$.
Moreover, several cases wherein melanoma was diagnosed after laser treatment of presumed benign nevi have been recently described [11-21]. It is still unclear whether the lesions were primary malignant melanomas treated with laser or if a malignant melanoma was induced by the laser treatment. Presumably, most cases represent an incorrect treatment based on a clinical misdiagnosis. However, a modification of the melanocytic lesion induced by the invasive procedure could not be ruled out in some cases, since the interval between laser therapy and progression was conspicuously short $[11,13]$. Table 1 summarizes a collection series of patients who developed melanoma or pseudomelanoma subsequent to treatment of a melanocytic lesion with laser, obtained from MEDLINE-cited journals.

\section{Conclusion}

In this case, fortunately, the dermoscopic characteristics of the lesion prior to IPL treatment and the follow-up supported the diagnosis of a benign melanocytic nevus. The presence of dermoscopic mi- 
Table 1. Collection series of patients who developed melanoma or pseudomelanoma subsequent to treatment of a melanocytic lesion with laser

\begin{tabular}{|c|c|c|c|c|c|c|c|}
\hline First author & $\begin{array}{l}\text { Age/ } \\
\text { sex }\end{array}$ & Location & $\begin{array}{l}\text { Initial clinical } \\
\text { evaluation }\end{array}$ & Laser type & Histologic diagnosis & $\begin{array}{l}\text { Interval from } \\
\text { laser treatment } \\
\text { to diagnosis }\end{array}$ & $\begin{array}{l}\text { Metastasis at } \\
\text { follow-up }\end{array}$ \\
\hline Arndt, 1986 [16] & $64 / \mathrm{M}$ & none & LM & argon & LM & 4 years & - \\
\hline Trau, 1986 [8] & $45 / \mathrm{F}$ & back & congenital nevus & $\mathrm{CO}_{2}$ & pseudomelanoma & 4 months & - \\
\hline $\begin{array}{l}\text { Dummer, } 1998 \\
{[10]}\end{array}$ & $44 / \mathrm{F}$ & upper leg & pigmented nevus & $\mathrm{CO}_{2}$ & pseudomelanoma & 6 weeks & - \\
\hline Lee, 1998 [21] & $71 / \mathrm{M}$ & cheek & $\begin{array}{l}\text { pigmented actinic } \\
\text { keratosis }\end{array}$ & QSRL & LM & 1 year & - \\
\hline Lee, 1998 [21] & $59 / \mathrm{M}$ & cheek & lentigo & QSRL & LMM & 30 months & - \\
\hline Grob, 1999 [15] & $47 / \mathrm{M}$ & - & red papular lesion & $\mathrm{CO}_{2}$ & amelanotic MM & 1 year & - \\
\hline Hwang, 2002 [9] & $18 / \mathrm{M}$ & chin & congenital nevus & $\begin{array}{l}\mathrm{CO}_{2} / \mathrm{QSRL} / \\
\text { alexandrite }\end{array}$ & pseudomelanoma & 43 months & - \\
\hline Böer, 2003 [17] & $37 / \mathrm{F}$ & shoulder & flesh-colored papule & ablative laser & nodular MM & several months & $\begin{array}{l}\text { subcutaneous cellular } \\
\text { tissue metastasis }\end{array}$ \\
\hline Böer, 2003 [17] & $54 / \mathrm{F}$ & cleavage & melanocytic nevus & ablative laser & MM & several months & - \\
\hline $\begin{array}{l}\text { Dummer, } 2003 \\
{[12]}\end{array}$ & $64 / \mathrm{F}$ & forehead & brownish macule & alexandrite & LMM & 6 months & lymph node metastasis \\
\hline $\begin{array}{l}\text { Dummer, } 2003 \\
{[12]}\end{array}$ & $? / \mathrm{F}$ & right arm & $\begin{array}{l}\text { brownish papular } \\
\text { lesion }\end{array}$ & $\mathrm{CO}_{2}$ & MM & 12 months & lymph node metastasis \\
\hline $\begin{array}{l}\text { Woodrow, } 2003 \\
{[14]}\end{array}$ & $27 / \mathrm{F}$ & upper back & $\begin{array}{l}\text { giant congenital } \\
\text { nevus }\end{array}$ & argon & SMM & 11 years & - \\
\hline $\begin{array}{l}\text { Gottschaller, } \\
2006[13]\end{array}$ & $64 / \mathrm{F}$ & cheek & lentigo & $\mathrm{CO}_{2}$ & N/A & 3 years & parotid gland metastasis \\
\hline Lee, 2006 [7] & $16 / \mathrm{F}$ & $\begin{array}{l}\text { upper } \\
\text { extremity }\end{array}$ & congenital nevus & $\begin{array}{l}\mathrm{CO}_{2} / \text { erbium/ } \\
\text { alexandrite }\end{array}$ & pseudomelanoma & - & - \\
\hline $\begin{array}{l}\text { Giacomel, } 2008 \\
{[11]}\end{array}$ & $42 / \mathrm{F}$ & back & small black nodule & N/A & $\begin{array}{l}\text { invasive melanoma } \\
\text { with satellite metastasis }\end{array}$ & N/A & $\begin{array}{l}\text { hepatic, pulmonary and } \\
\text { intracranial metastasis }\end{array}$ \\
\hline Zipser, 2010 [2] & $52 / \mathrm{F}$ & cheek & seborrheic keratosis & $\mathrm{CO}_{2} /$ erbium & MM not classifiable & 80 months & - \\
\hline Zipser, 2010 [2] & $72 / \mathrm{M}$ & forehead & melanocytic nevus & N/A & LMM & 20 months & - \\
\hline Zipser, $2010[2]$ & $66 / \mathrm{M}$ & lentigo & lentigo & $\mathrm{CO}_{2}$ & LM & 7 years & - \\
\hline Zipser, 2010 [2] & $75 / \mathrm{F}$ & preauricular & N/A & $\mathrm{CO}_{2}$ & LM & $\mathrm{N} / \mathrm{A}$ & - \\
\hline Zipser, 2010 [2] & $63 / \mathrm{F}$ & mandibular & melanocytic nevus & N/A & SSM & 6 months & - \\
\hline Zipser, 2010 [2] & $46 / \mathrm{F}$ & eyebrow & melanocytic nevus & N/A & N/A & 9 months & - \\
\hline Zipser, 2010 [2] & $47 / \mathrm{M}$ & preauricular & verruca & $\mathrm{CO}_{2}$ & nodular MM & 1 year & - \\
\hline Zipser, $2010[2]$ & $21 / \mathrm{F}$ & upper arm & melanocytic nevus & N/A & ALM & 1 year & - \\
\hline Zipser, 2010 [2] & $45 / \mathrm{F}$ & forehead & verrucous nevus & N/A & NMM & 5 months & - \\
\hline Zipser, $2010[2]$ & $59 / \mathrm{F}$ & cheek & lentigo & erbium:YAG & LMM & 5 months & - \\
\hline Zipser, 2010 [2] & $75 / \mathrm{F}$ & upper arm & basal cell carcinoma & $\mathrm{CO}_{2}$ & NMM & 18 months & - \\
\hline Zipser, 2010 [2] & $40 / \mathrm{F}$ & under lower lip & lentigo & $\mathrm{CO}_{2}$ & nodular MM and ALM & 7 years & - \\
\hline
\end{tabular}

ALM = Acral-lentiginous melanoma; LM = lentigo maligna; LMM = lentigo maligna melanoma; $M M=$ melanoma; N/A = not available; $Q S R L=$ Q-switched ruby laser; SSM = superficial spreading melanoma.

crocrusts should help us in the diagnosis of pulsed light- or laser-induced regression of melanocytic nevi. When a laser-treated skin lesion is excised and examined histologically, it is absolutely essential that the dermatopathologist have as much clinical information as possible to establish a correct diagnosis and to avoid unnecessary surgical procedures, and other forms of adjuvant treatment and follow-up programs $[7,9,10]$.

Melanocytic lesions should not be considered a routine indication for laser therapy for cosmetic reasons [11, 13]. Moreover, clinically ambiguous skin tumors should never be treated with laser prior to a diagnostic biopsy. The first-choice treatment of equivocal skin lesions, particular- ly with a history of changes, remains excision with histopathologic examination [11].

\section{Disclosure Statement}

The authors have no financial support or conflicts of interest to disclose. 


\section{References}

1 Greve B, Raulin C: Professional errors caused by lasers and intense pulsed light technology in dermatology and aesthetic medicine: preventive strategies and case studies. Dermatol Surg 2002;28:156-161.

-2 Zipser MC, Mangana J, Oberholzer PA, French LE, Dummer R: Melanoma after laser therapy of pigmented lesions - circumstances and outcome. Eur J Dermatol 2010;20: 334-338.

$>3$ Yamashita T, Kuwahara T, Gonzalez S, Takahashi M: Non-invasive visualization of melanin and melanocytes by reflectance-mode confocal microscopy. J Invest Dermatol 2005; 124:235-240.

-4 Moreno-Arias GA, Ferrando J: Intense pulsed light for melanocytic lesions. Dermatol Surg 2001;27:397-400.

$\checkmark 5$ Yamashita T, Negishi K, Hariya T, et al: Intense pulsed light therapy for superficial pigmented lesions evaluated by reflectancemode confocal microscopy and optical coherence tomography. J Invest Dermatol 2006;126:2281-2286.

6 Kawada A, Shiraishi H, Asai M, et al: Clinical improvement of solar lentigines and ephelides with an intense pulsed light source. Dermatol Surg 2002;28:504-508.
7 Lee HW, Ahn SJ, Lee MW, Choi JH, Moon KC, Koh JK: Pseudomelanoma following laser therapy. J Eur Acad Dermatol Venereol 2006;20:342-343.

-8 Trau H, Orenstein A, Schewach-Millet M, et al: Pseudomelanoma following laser therapy for congenital nevus. J Dermatol Surg Oncol 1986;12:984-986.

$>9$ Hwang K, Lee WJ, Lee SI: Pseudomelanoma after laser therapy. Ann Plast Surg 2002;48 562-564.

$>10$ Dummer R, Kempf W, Burg G: Pseudo-melanoma after laser therapy. Dermatology 1998;197:71-73.

11 Giacomel J, Zalaudek I, Mordente I, Nicolino R, Argenziano G: Never perform laser treatment of skin tumors with clinical 'EFG' criteria. J Dtsch Dermatol Ges 2008;6:386-388.

12 Dummer R: About moles, melanomas, and lasers: the dermatologist's schizophrenic attitude toward pigmented lesions. Arch Dermatol 2003;139:1405-1406.

13 Gottschaller C, Hohenleutner U, Landthaler M: Metastasis of a malignant melanoma 2 years after carbon dioxide laser treatment of a pigmented lesion: case report and review of the literature. Acta Derm Venereol 2006;86: 44-47.

14 Woodrow SL, Burrows NP: Malignant melanoma occurring at the periphery of a giant congenital naevus previously treated with laser therapy. Br J Dermatol 2003;149:886888 .
15 Grob M, Senti G, Dummer R: Delay of the diagnosis of an amelanotic melanoma due to $\mathrm{CO}_{2}$-laser treatment - case report and discussion. Schweiz Rundsch Med Prax 1999; 88:1491-1494.

16 Arndt KA: New pigmented macule appearing 4 years after argon laser treatment of lentigo maligna. J Am Acad Dermatol 1986;14: 1092.

17 Böer A, Wolter M, Kaufmann R: Pseudomelanoma following laser treatment of lasertreated melanoma? J Dtsch Dermatol Ges 2003;1:47-50.

18 Kutzner $\mathrm{H}$ : Under the microscope: laser, Shave, IGEL and their outcome. Dtsch Dermatol 2001;8:248-253.

19 Niiyama N, Niiyama S, Takasu H, et al: Progression of lentigo maligna into lentigo maligna melanoma following laser treatment. Eur J Dermatol 2007;17:252-253.

20 Hilker O, Mainusch O: Lentigo maligna melanoma after laser treatment. Journal of the Helios Centre of Dermatology Wuppertal 2004;3:1-2.

21 Lee PK, Rosenberg CN, Tsao H, et al: Failure of Q-switched ruby laser to eradicate atypical-appearing solar lentigo: report of two cases. J Am Acad Dermatol 1998;38:314-317. 